\title{
Microstructure and Transformation Characteristics of a TiAlNb Alloy with Cr and Mo Addition
}

\author{
Santirat Nansaarng*, Panya Srichandr \\ Division of Materials Technology, School of Energy, Environment and Materials, \\ King Mongkut's University of Technology Thonburi (KMUTT), Bangkok, 10140, Thailand
}

Received: May 28, 2011; Revised: September 15, 2011

\begin{abstract}
The present study investigated the Ti-46Al-4Nb-2Mo and Ti-46Al-4Nb-2Cr (at.\%) alloys, which were prepared by solution treatment at $1,400^{\circ} \mathrm{C}$ for 30 minutes prior to being air-cooled. The alloys were subsequently reheated to $1,350^{\circ} \mathrm{C}$ for 60 minutes and were cooled to room temperature by oil or water quenching. The evolution of the microstructure in the alloys was investigated by detailed characterization of the massive- $\gamma$ transformation of the heat-treated samples by optical microscopy and electron backscatter diffraction (EBSD). Lamellar structures consisting of and $\alpha_{2}$ phases with small amounts of $\beta$-phase were distributed along the grain boundary after the solution treatment process in both alloys. A massive- $\gamma$ transformation from the $\alpha$-phase field was observed for the samples that were cooled by water or oil quenching. After cooling in either oil or water, the massive- $\gamma$ transformed structure of Ti-46Al-4Nb-2Cr without a lamellar phase was distributed on the $\alpha_{2}$-matrix. In addition, the massive- $\gamma$ phases confirmed that the nucleation site was at the grain boundary of the $\alpha / \alpha$ parent phase. Moreover, the volume fraction of massive- $\gamma$ decreased as the cooling rate increased. The EBSD results demonstrated that the massive- $\gamma$ transformation inherited the orientation of the lamellar- $\gamma$, and nucleation occurred around the parent $\alpha$-matrix. The detailed observation orientation relationship by Kikuchi patterns and pole figures revealed a massive- transformation, and the $\alpha_{2}$-matrix had the associated orientation relationship from the $\gamma$-lamellar and parent $\alpha$-matrix.
\end{abstract}

Keywords: massive- $\gamma$, EBSD technique, phase transformation, alloying elements, heat treatment

\section{Introduction}

Titanium aluminides are potential candidates for structural high-temperature components, particularly in aerospace and automotive applications, because of their low density, high melting temperature, high specific tensile strength, strength at elevated temperatures and strong oxidation resistance ${ }^{1-3}$. Titanium aluminides, however, have lower formality, and the production and forming processes are technically difficult. Among the titanium aluminides, the $\gamma$-TiAl alloy group is the most popular for industrial services because the two-phase structure between $\alpha_{2}\left(\mathrm{Ti}_{3} \mathrm{Al}\right)$ and $\gamma(\mathrm{TiAl})$ results in improved mechanical properties. The microstructure and mechanical properties of TiAl alloys are strongly influenced by both the chemical composition and the heat-treatment procedures employed. Regarding the chemical composition, alloying with a ternary or quaternary element (e.g., $\mathrm{Nb}, \mathrm{Mo}, \mathrm{Cr}, \mathrm{V}, \mathrm{B}$, or $\mathrm{Si}$ ) can have significant effects on the microstructure and the mechanical properties of the alloys ${ }^{4,5}$. The microstructure is ultimately controlled by the heat treatment, and the cooling rate is particularly important in determining the microstructure of titanium aluminides because phase transformation mechanisms control the final nature of the microstructure ${ }^{6}$. Studies by Wu et al. ${ }^{7,8}$ found that improvements in the mechanical properties of cast titanium aluminides were due to the effects of the casting process on the microstructure. Indeed,

*e-mail: santirat.nan@kmutt.ac.th massive- $\gamma$ phases can be formed from a single $\alpha$-phase field by a partitionless transformation, which is initiated by varying the cooling rate. Studies have also shown that the addition of alloying elements, such as $\mathrm{Nb}, \mathrm{Mn}^{9}$ and $\mathrm{Ta}^{10}$, have a greater effect on the transformation because they increase the effective range of cooling rates and promote massive- $\gamma$ formation. Many studies have investigated the phase transformation mechanisms for the $\alpha$-phase (at high temperatures) transformation to the $\alpha_{2}$ and $\gamma$-lamellar form or to massive- $\gamma$. Interestingly, two massive transformation processes have received considerable attention for refining the microstructure and improving the mechanical properties of casting products ${ }^{7}$. Several previous studies have focused on the ternary composition, the nucleation process, and the orientation relationship between the parent $\alpha$-phase and the product massive- $\gamma$ phase ${ }^{7,9}$. In addition, alternative techniques, such as the EBSD technique, have explored the nucleation mechanism of the massive transformed- $\gamma$ phase to explain phase orientation that is developed at the $\alpha / \alpha$ parent phase grain boundary and through orientation between lamellar structure and massive structure ${ }^{11}$. The aim of the present work was to study the effect of alloying elements (e.g., $\mathrm{Nb}, \mathrm{Mo}$, and $\mathrm{Cr}$ ) and the cooling rate on the massive- $\gamma$ phase transformation and phase characteristics of TiAl alloys (Ti-46Al-4Nb-2Mo and Ti-46Al-4Nb-2Cr) using the EBSD technique. 


\section{Materials and Methods}

Ti-46Al-4Nb-2Mo and Ti-46Al-4Nb-2Cr (at. \%) alloys were prepared using the non-consumable vacuum arc melting technique in an argon atmosphere. Button ingots that weighed approximately $60 \mathrm{~g}$ were re-melted at least five times to ensure the homogeneity of the chemical composition. Samples were cut from the as-cast buttons by wire-electrical-discharge machining. Next, the samples were solution-treated by soaking at the temperature of the $\alpha$ single-phase area $\left(1,400{ }^{\circ} \mathrm{C}\right)$ for 30 minutes and subsequently air-cooled (AC). Next, the solution-treated samples (nominal dimensions of $10 \times 10 \times 10 \mathrm{~mm}$ ) were heat-treated at $1,350{ }^{\circ} \mathrm{C}$ for 60 minutes and quenched in either oil quenching (OQ) and water quenching (WQ), which produces different microstructures.

All of the heat-treated samples were abraded with SiCbased emery paper to remove the oxidized surface layer, rinsed with water, polished to a $0.1-\mu \mathrm{m}$ finish with a diamond suspension abrasive, and etched using Kroll's regent $(5 \mathrm{~mL}$ $\mathrm{HF}, 10 \mathrm{~mL} \mathrm{HNO}_{3}$, and $85 \mathrm{~mL} \mathrm{H}_{2} \mathrm{O}$ ). The microstructures

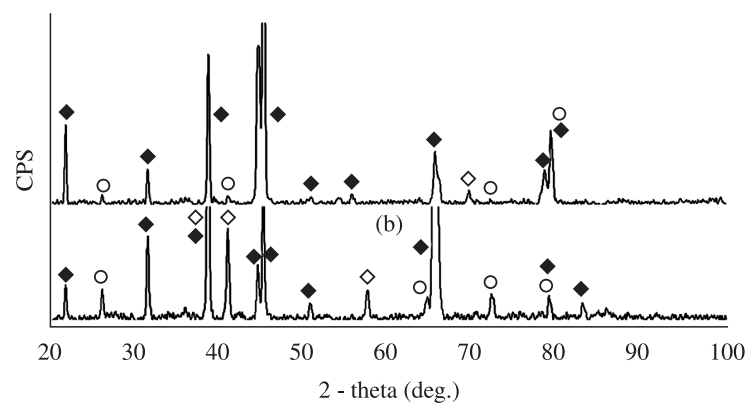

(a)

$\diamond \operatorname{Beta}(\mathrm{Ti}) \diamond \mathrm{TiAl} \circ \mathrm{Ti}_{3} \mathrm{Al}$

Figure 1. X-ray diffraction patterns of the two alloys in as-received condition revealed three phases: $\gamma, \alpha$ and $\beta$ phases. a) Ti-46Al-4Nb$2 \mathrm{Mo}$, and b) Ti-46Al-4Nb-2Cr.

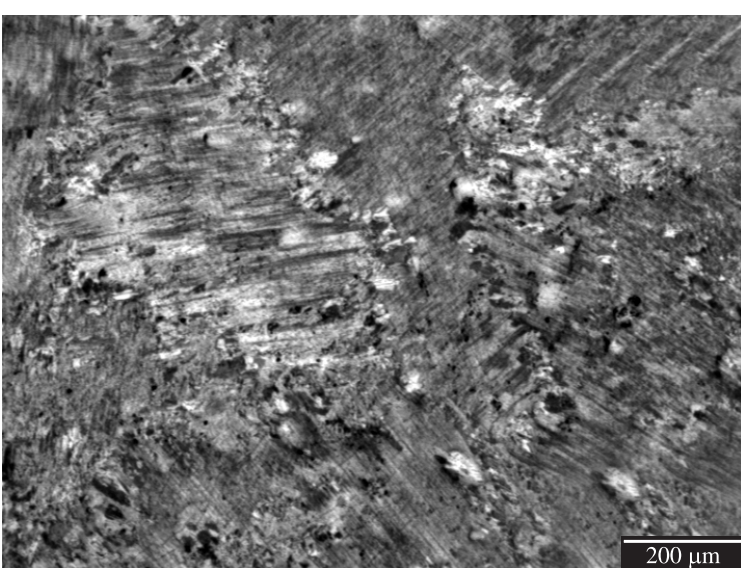

(a) and resultant phases in the heat-treated samples were studied using X-ray diffraction (XRD), an optical microscope with a Leica Q-Phase image analyzer, scanning electron microscopy (SEM), back-scattered electron detection (BSE) and electron backscatter diffraction (EBSD).

\section{Results}

\subsection{Solution treatment}

Figure 1 shows the XRD patterns of Ti-46Al-4Nb-2Mo and $\mathrm{Ti}-46 \mathrm{Al}-4 \mathrm{Nb}-2 \mathrm{Cr}$ samples in as-received condition (that is, solution-treated at $1,400{ }^{\circ} \mathrm{C}$ for 30 minutes and air-cooled). The diffraction peaks confirmed that the alloys primarily consisted of the $\gamma$-TiAl phase with minor amounts of the $\alpha_{2}-\mathrm{Ti}_{3} \mathrm{Al}$ phase and the $\beta$ phase. The optical micrographs showed a typical lamellar microstructure, which consisted of alternate layers of $\gamma, \alpha_{2}$ and $\beta$ phases. There was a small volume fraction of equiaxed regions within the lamellar structure of the Ti-46Al-4Nb-2Mo and Ti-46Al-4Nb-2Cr alloys (Figure $2 \mathrm{a}$ and $2 \mathrm{~b}$ ). The equiaxed microstructure of the Ti-46Al-4Nb-2Cr alloy sample more pronounced than the other samples (approximately 20\% equiaxed structure). The BSE images of both the Ti-46Al$4 \mathrm{Nb}-2 \mathrm{Mo}$ and $\mathrm{Ti}-46 \mathrm{Al}-4 \mathrm{Nb}-2 \mathrm{Cr}$ alloys (Figure $3 \mathrm{a}$ and $3 \mathrm{~b}$ ) showed evidence of the $\beta$ phase along the colony boundaries and distributed in the lamellar- $\gamma$ matrix.

\subsection{Microstructures}

Representative optical micrographs of Ti-46Al-4Nb$2 \mathrm{Mo}$ and $\mathrm{Ti}-46 \mathrm{Al}-4 \mathrm{Nb}-2 \mathrm{Cr}$ samples directly quenched using either oil or water from $1,350{ }^{\circ} \mathrm{C}$ are shown in Figure 4. In addition, Figures $4 \mathrm{a}-\mathrm{d}$ also show the structure of the massive- $\gamma$ transformation on the matrix of $\alpha_{2}$ and its distribution over the area of the cross section, which is different from the structure observed in the solutiontreated samples where the massive- $\gamma$ structure was not found. Interestingly, we found that the Ti-46Al-4Nb-2Mo sample had significantly more massive- structure than did the Ti-46Al-4Nb-2Cr sample. In the microstructure of

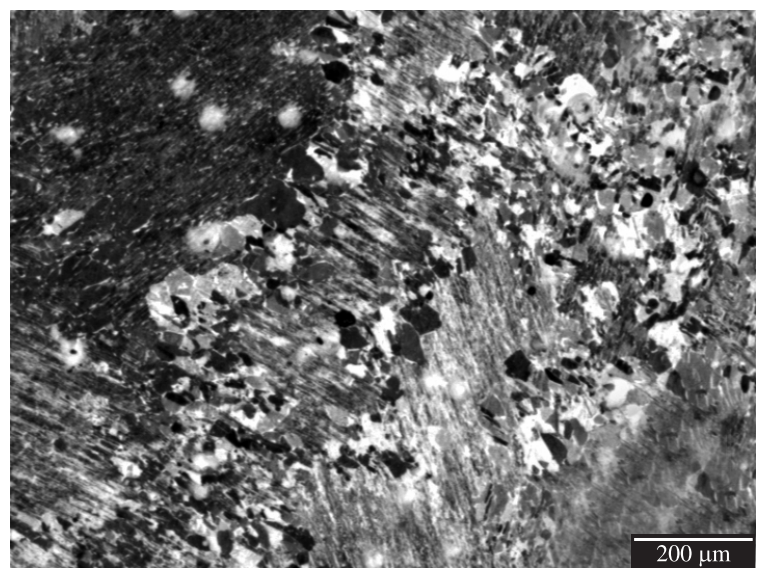

(b)

Figure 2. Microstructure of the as-received condition, which shows the lamellar and equiaxed structure of: a) Ti-46Al-4Nb-2Mo, and b) $\mathrm{Ti}-46 \mathrm{Al}-4 \mathrm{Nb}-2 \mathrm{Cr}$. 


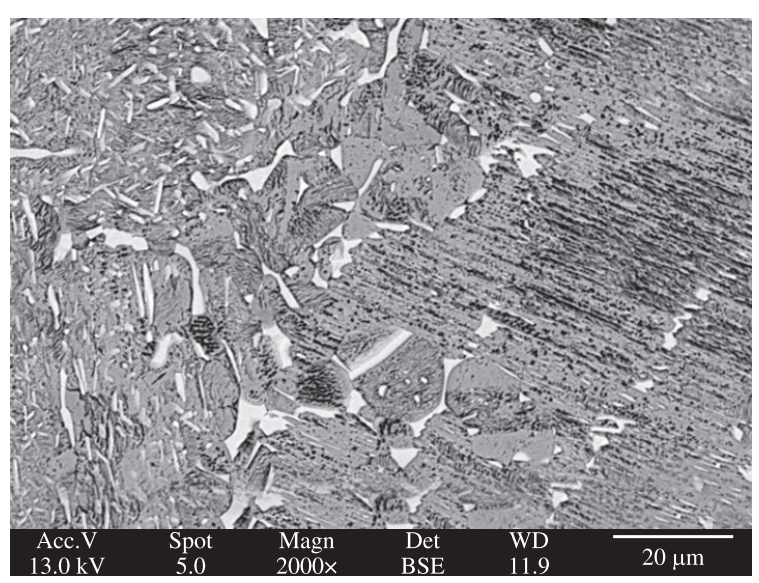

(a)

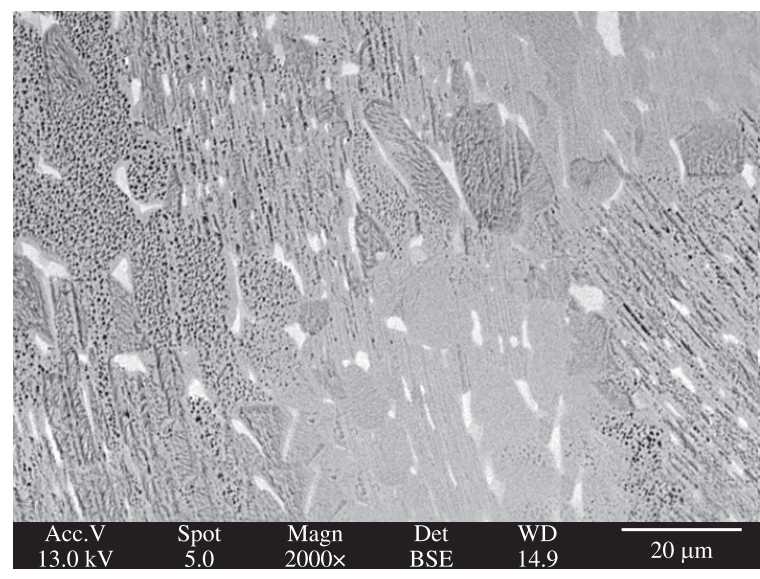

(b)

Figure 3. BSE images of the $\beta$-phase (bright field) of the two alloys in as-received condition, which shows the $\beta$-phase distributed along the grain boundary in: a) Ti-46Al-4Nb-2Mo, and b) Ti-46Al-4Nb-2Cr.

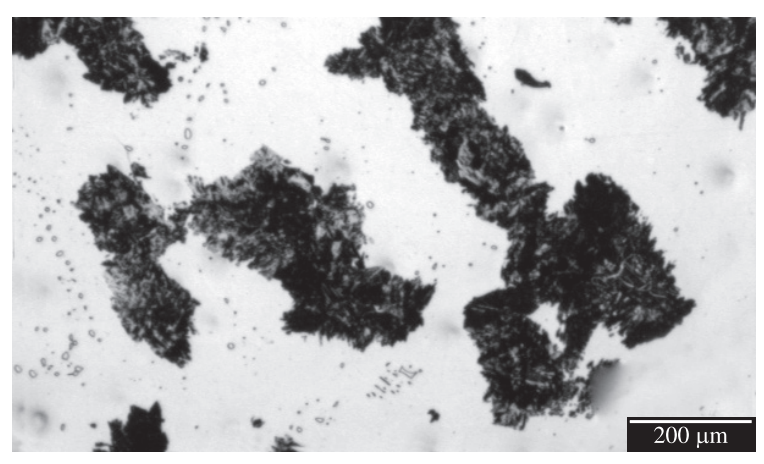

(a)

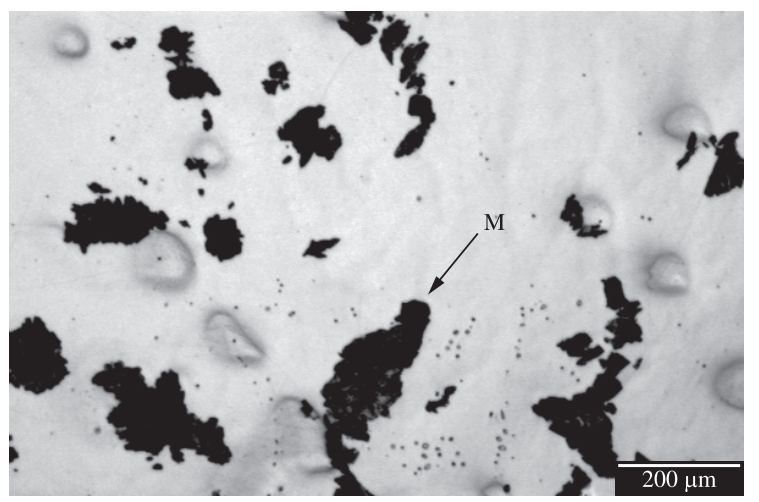

(c)

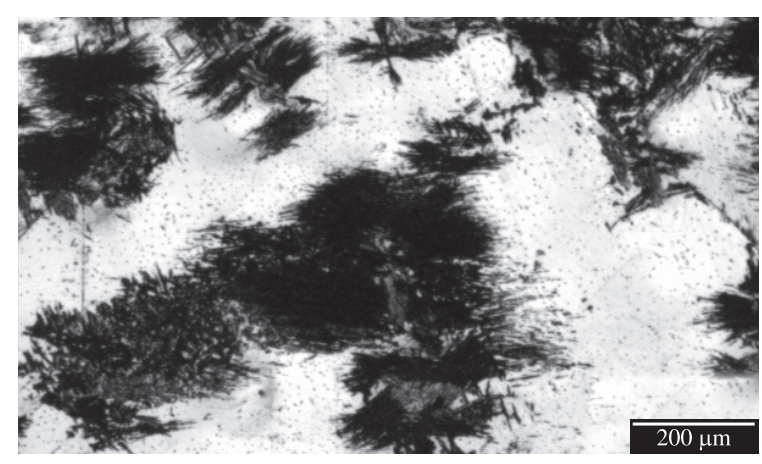

(b)

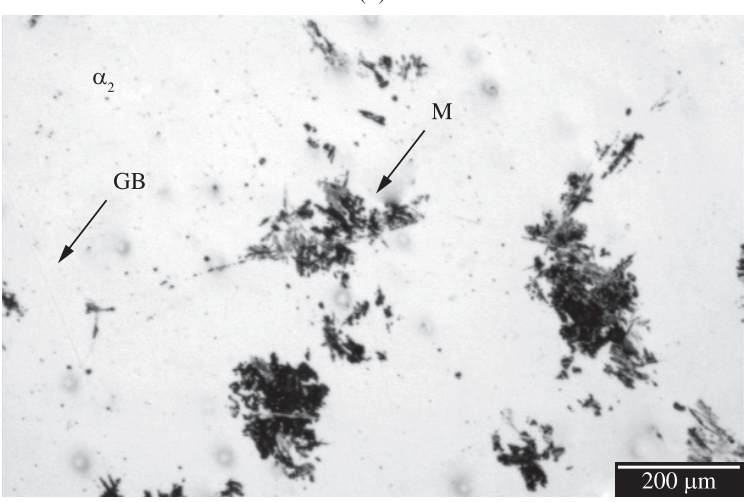

(d)

Figure 4. Micrographs of Ti-46Al-4Nb-2Mo and Ti-46Al-4Nb-2Cr oil and water quenched from $1,350{ }^{\circ} \mathrm{C}$. All samples showed a massive- $\gamma$ transformed phase (M) that resembled a small island (dark) distributed on an $\alpha_{2}$ - matrix (bright): a,c) show microstructures of Ti-46Al-4Nb-2Mo cooled by oil and water quenching, respectively, b,d) show microstructures of Ti-46Al-4Nb-2Cr cooled by oil and water quenching, respectively.

Ti-46Al-4Nb-2Mo with OQ cooling, the massive- $\gamma$ phase distribution was present in the $\alpha_{2}$-matrix. These massive- $\gamma$ phase regions look similar to small islands (dark) that surround the $\alpha_{2}$-matrix, but the nucleated site is not clear because we could not find the grain boundary (Figure 4a, which had a volume fraction of approximately $45 \%$ ). The microstructure of Ti-46Al-4Nb-2Cr (Figure 4b) was large- grained and mainly consisted of colonies of massive- $\gamma+\alpha_{2}$ phase (the massive- $\gamma$ colony size was approximately $350-500 \mu \mathrm{m})$. The nucleation of massive- $\gamma$ was transformed at the grain boundary, and there was subsequent growth into the grain. The microstructures of Ti-46Al-4Nb-2Mo cooled by WQ, however, revealed a massive- $\gamma$ structure (dark in appearance) on the $\alpha_{2}$-massive matrix (light in appearance) 


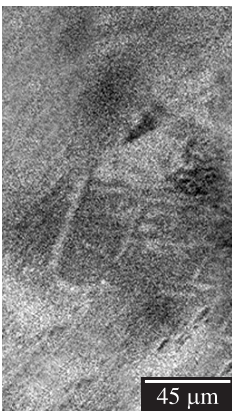

(a)

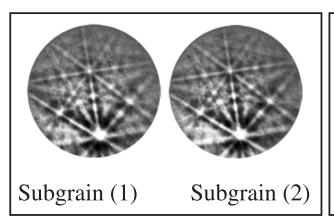

(d)

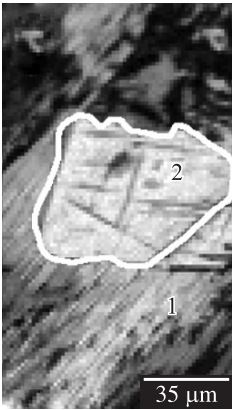

(b)

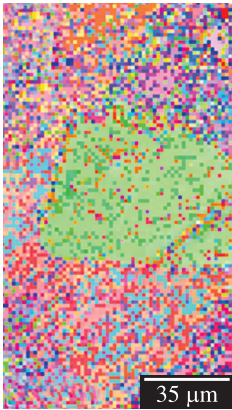

(c)

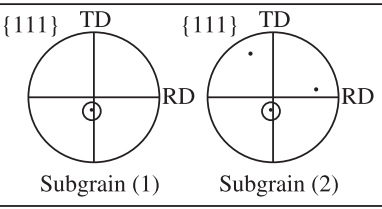

(e)

Figure 5. Micrographs and diffraction patterns from a sample of Ti-46Al-4Nb-2Mo oil quenched from $1,350^{\circ} \mathrm{C}$. a) A backscattered scanning electron micrograph image, and b) an EBSD image showing that the massive- $\gamma$ was associated with gamma in the lamellae form (subgrain 1). c) An EBSD image showing different colored areas. d) Kikuchi maps, and e) pole figures of massive- $\gamma$ and lamellar structure marked as subgrains 1 and 2 show that they have identical orientation, which suggests that subgrain 1 was the formation of the twin-related to subgrain 2 .

with an approximately $21 \%$ volume fraction of massive- $\gamma$ phase (Figure 4c). For the Ti-46Al-4Nb-2Cr alloy, the microstructures consisted of a featureless bright $\alpha_{2}$-matrix with fine acicular patches of massive- $\gamma$ structure dispersed on the matrix. In addition, nucleation appeared to start at the $\alpha_{2}$ grain boundaries (colony size $\sim 30-200 \mu \mathrm{m}$ ). The volume fraction of this massive- $\gamma$ phase was approximately $15 \%$ (Figure 4d).

The EBSD results from the Ti-46Al-4Nb-2Mo sample quenched by oil are shown in Figure 5 . The backscattered image in Figure 5a and the EBSD image in Figure 5b show that the massive- $\gamma$ transformation was associated with gamma in the lamellar- $\gamma$ form. The EBSD image in Figure 5c shows that there were different orientations between the lamellar- $\gamma$ (labeled 1) and massively transformed- $\gamma$ (labeled 2) regions. When considering the two regions in the image, it was determined that they were not associated with orientation. Importantly, the Kikuchi maps shown in Figure $5 d$ confirmed that the massive- $\gamma$ in subgrain 2 had the same orientation as the lamellar- $\gamma$ in subgrain 1. The stereograms in Figure 5e revealed information about the involvement of subgrain 1 and subgrain 2 , and we determined that subgrain 1 was related to subgrain 2; thus, the twin phenomenon, which was reported by S.R. Dey et al. ${ }^{11}$, was confirmed. Indeed, the growth of the massive structure was created from the low-stacking-fault energy and the nucleated twinning over the $\{111\}$ plane.

The EBSD image in Figure 6a shows the massive- $\gamma$ structure of the Ti-46Al-4Nb-2Cr OQ sample. Figure $6 \mathrm{~b}$ shows the difference between the two regions with dark and light areas, which indicate the occurrence of massive- $\gamma$.

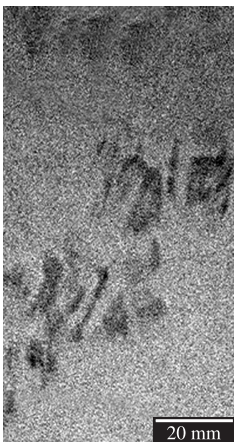

(a)

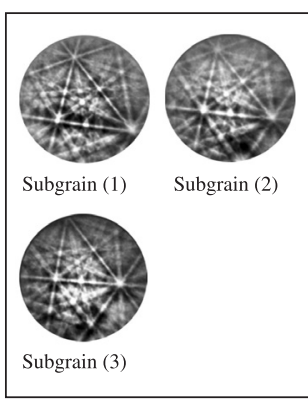

(d)

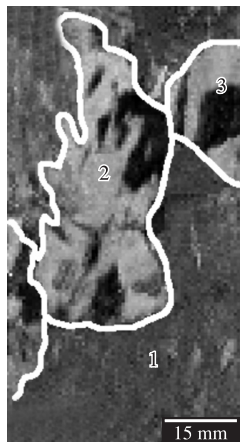

(b)

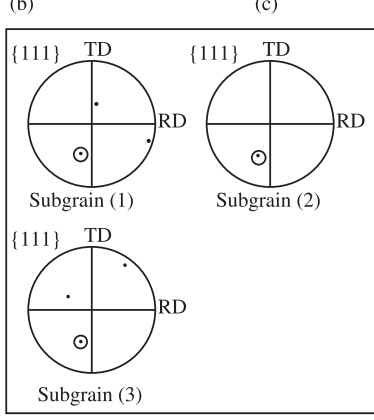

(e)

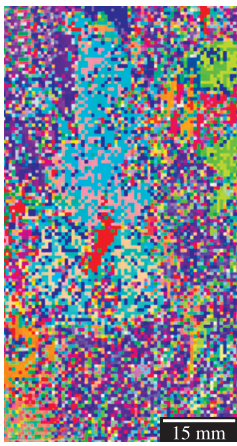

(c)
Figure 6. Micrographs and diffraction patterns from a sample of Ti-46Al-4Nb-2Cr oil quenched from $1,350{ }^{\circ} \mathrm{C}$. a) A backscattered scanning electron micrograph image, and b) an EBSD image showing the difference between the two regions with dark and light areas, which indicate the occurrence of massive- $\gamma$. c) An EBSD image, d) Kikuchi maps, and e) pole figures of subgrains 1, 2 and 3 show that the the massive- $\gamma$ transformed structure within subgrains 2 and 3 was nucleated from twin-related to subgrain 1 with the (111) plane.

The EBSD image in Figure 6c explains the orientation relationships as subgrain 1, subgrain 2 and subgrain 3 . The overall results of the microstructures in the three subgrains revealed the massive- $\gamma$ transformed structure. The orientation relationships of all three subgrains from the Kikuchi maps shown in Figure 6d confirmed that the massively transformed structure within subgrain 2 and subgrain 3 were nucleated from twin-related regions in subgrain 1 in the (111) plane. The orientation relationships were also confirmed by the pole figure in Figure 6e.

Figure 7 shows the microstructure of Ti-46Al4Nb2Mo cooled by WQ. The EBSD images in Figures $7 \mathrm{a}-\mathrm{c}$ show the components of the lamellar structure (region 1) and massive- $\gamma$ structure (region 2 ). These finding is apparently from the color region in the EBSD image and from the associated pole figures and corresponding Kikuchi maps shown in Figures 7c-e. The Kikuchi maps shown in Figure $7 d$ confirm that the massive- $\gamma$ in region 2 has the identical orientation with lamellar in region 1 . The stereograms in Figure 7e from the lamellar and massive- $\gamma$ region, show that the massive- $\gamma$ in region 2 is parallel with a (111) in region 2 and twin-related to region 1 with (111) plane.

Samples of Ti-46Al-4Nb-2Cr quenched in water exhibited massive- $\gamma$ transformation (Figures $8 \mathrm{a}-\mathrm{d}$ ). The microstructure of the $\mathrm{Ti}-46 \mathrm{Al}-4 \mathrm{Nb}-2 \mathrm{Cr}$ sample showed a 


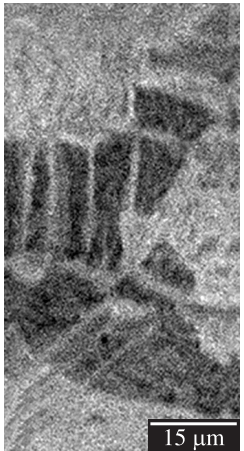

(a)

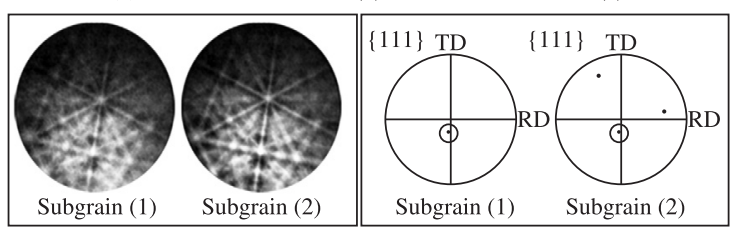

(d)

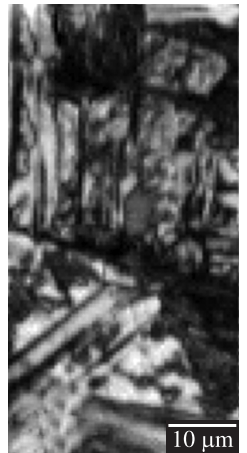

(b)

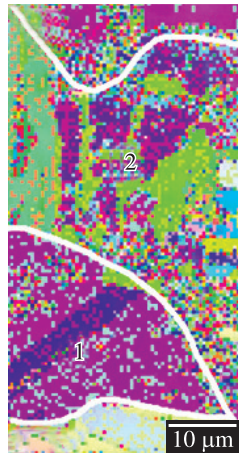

(c)

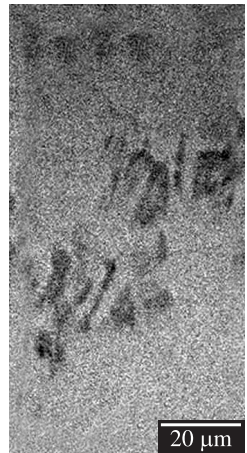

(a)

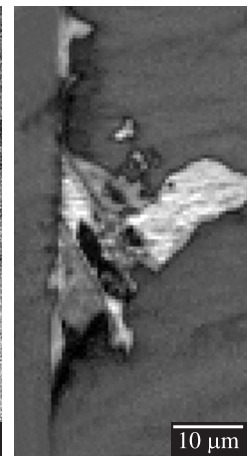

(b)

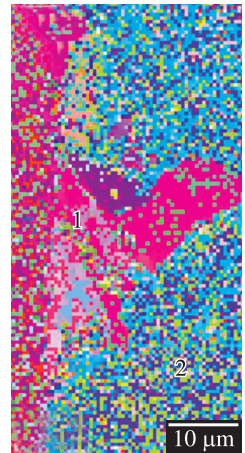

(c)

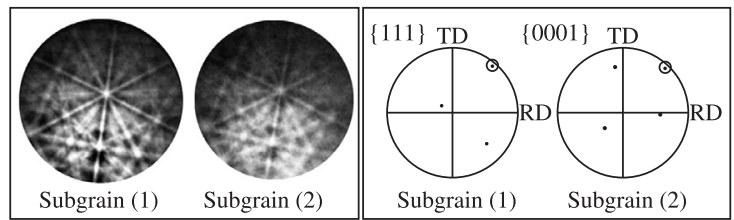

(d)

Figure 7. Micrographs and diffraction patterns from a sample of Ti46Al-4Nb-2Mo water quenched from $1,350^{\circ} \mathrm{C}$. a) A backscattered scanning electron micrograph image, and b) an EBSD image showing that the massive- $\gamma$ was associated with gamma in the lamellae form (subgrain 1). c) An EBSD image, d) Kikuchi maps, and e) pole figures of subgrains 1 and 2 show the Kikuchi maps taken from regions 1 and 2 and the poles to the $\{111\}$ plane. The two regions have the same orientation, and region 2 was twinrelated to region 1 .

similar transformation as the previous case (Ti-46Al4Nb2Mo cooled by WQ); however, the Ti-46Al-4Nb-2Cr sample showed a clear nucleation site of the massive- $\gamma$ formation. Figure $8 \mathrm{~b}$ shows that the massive- $\gamma$ was nucleated at the grain boundary and grew into the parent phase (as a small island). In addition, there was more structure contrast in the two regions. The $\{111\}$ pole figure and Kikuchi maps from Figures $8 d$ and e show that the massive- $\gamma$ (region 1) and alpha parent phase (region 2) had the same orientation relationship. Indeed, the matrix (0001) of the alpha parent phase was parallel with the (111) plane in region 1 of the massive- $\gamma$.

Although samples were cooled down using different media (i.e., oil or water), the relationship between the matrix structure, alpha phase and massive- $\gamma$ of the samples indicated that the structural transformation was the same in each composition. Alloying with $\mathrm{Mo}$ and $\mathrm{Cr}$, however, resulted in different microstructures. The addition of $\mathrm{Cr}$ could clearly be observed for the massive transformation because the microstructure revealed the massive- $\gamma$ and alpha parent phase without the lamellar structure (Figures 6 and 8).

\section{Discussion}

The different amounts of alloying elements selected in the present study resulted in phase transformations at temperatures greater than the eutectoid temperature by subsequent quenching in two different media (i.e., oil and water). The microstructures of samples formed by solution treatment showed that both alloys had two types

Figure 8. Micrographs and diffraction patterns from a sample of Ti-46Al-4Nb-2Cr water quenched from $1,350^{\circ} \mathrm{C}$. a) A backscattered scanning electron micrograph image, and b) an EBSD image showing that massive- $\gamma$ was nucleated at the grain boundary and grew into the parent phase (like a small island). c) An EBSD image, d) Kikuchi maps, and e) pole figures of subgrains 1 and 2 show that the massive- $\gamma$ was nucleated at the grain boundary and grew into the parent phase (resembling a small island). In addition, more structure contrast was seen in the two regions, and the association between the massive- $\gamma$ (region 1) and the alpha parent phase (region 2) had the same orientation. Indeed, the relationship between the matrix (0001) of the alpha phase was parallel with (111) plane in the massive- $\gamma$.

of structure (i.e., full lamellar and small random regions of equiaxed $\alpha_{2}$ phase and phase). The Ti-46Al-4Nb-2Mo had a finer colony size than the Ti-46Al-4Nb-2Cr alloys; however, the Ti-46Al-4Nb-2Cr alloy exhibited the highest volume fraction of transformed equiaxed microstructure at the grain boundaries. Sreenivasulu et al..$^{5}$ reported that decreasing $\mathrm{Nb}$ and increasing Mo increased the volume fraction of transformed equiaxed microstructures compared with Ti-46Al-4Nb-2Cr; therefore, the kinetics of lamellar to equiaxed transformation are decreased by $\mathrm{Nb}$ and increased by Mo. The addition of Mo resulted in increased stability in the $\beta$ phase. The BSE images revealed that Mo more strongly segregated the $\beta$ phase compared with $\mathrm{Nb}$ and $\mathrm{Cr}$ (Figure $3 \mathrm{a}$ and $3 \mathrm{~b}$ ). Imayev et al. ${ }^{12}$ confirmed that $\mathrm{Nb}$ and Mo effectively improve the kinetically stabilized $\beta$ phase along the $\alpha$ grain boundaries and hinder the growth of $\alpha$ grains passing through the $\alpha$ single-phase field. Indeed, the addition of Mo expands the $\beta$ phase region toward the $\alpha$-phase and $\gamma$-phase regions in the isothermal section of the ternary phase system ${ }^{13}$. When heat-treated, diffusion of Mo and $\mathrm{Al}$ occurs in opposite directions, which tends to equilibrate these gradients, and zones of microstructure exist, depending upon the extent to which diffusion has occurred. Interestingly, alloys with $\mathrm{Cr}$ and Mo addition from both the as-cast condition and after heat treatment demonstrated that alloying solidification happened in a single-phase $\beta$ region. Although segregation existed within 
the $\beta$ grains (forming a complete solidification stage), the composition gradients were not notably strong, and the structures seen within the $\beta$ grains were uniform. The distribution of $\beta$ phases was dominated by the primary post-solidification transformation, which resulted in the formation of a lath in the Mo-lean alloys and $\gamma$ plates that directly formed from the $\beta$ phase in the Mo-rich alloys ${ }^{14}$.

In the two investigated alloys that were subjected to solution treatments and cooled by oil and water quenching, we found that the phase transformations resulted in the same microstructures (i.e., massive- $\gamma$ with an $\alpha_{2}$-matrix). Interestingly, the addition of $\mathrm{Cr}$ had a greater effect on the massive transformation; however, the Mo alloys had a massive structure with some lamellar structures. When comparing the effect of quenching media on the quantity of massive structure formed, the volume fraction of massive- $\gamma$ formed by oil quenching was greater than by water quenching for both Ti-46Al-4Nb-2Mo and Ti-46Al-4Nb-2Cr. Because $\mathrm{Nb}$ has a low diffusivity in TiAl alloys, the formation of diffusion-related feathery/lamellar transformations is suppressed, which allows massive transformation to occur ${ }^{10}$. The addition of $\mathrm{Nb}$ also extends the massive regime in $\mathrm{TiAl}$ alloys toward rapid cooling rates observed between oil and water quenching. The addition of $\mathrm{Mo}$ and $\mathrm{Cr}$ in $\mathrm{TiAl}$ alloys was found to form similar feather-type microstructures as with the massive- $\gamma$ formed in both oil and water quenching.

The massive- $\gamma$ transformation mechanism has proved difficult to explain. The observation of the nuclei of the massive formation has been especially difficult to explain because the massive- $\gamma$ structure can nucleate from the lamellar structure above the usual massive transform temperature ${ }^{15}$. In addition, the massive- $\gamma$ structures can nucleate from single atom jump diffusional $\alpha \rightarrow \gamma$ phase transformations and spread in all directions with no large-scale composition change $^{16}$. Some proposed mechanisms have indicated that the transformation to massive- $\gamma$ occurs because of a twinning mechanism between the massive transformation processes. Thus, one strategy that can be used to consider massive transformation phenomenon is to observe the formation of twins in the (111) plane because this plane is the site of nucleation of massive- $\gamma$. If the twinning occurred at this point, the relationship could reveal the orientation between the massive transformation and the alpha matrix ${ }^{11}$. In the present study, we found that the massive- $\gamma$ formation was relevant to the alpha parent phase in all alloys with either water or oil quenching. The orientation relationship in this study was found to indicate that same orientation with $\{111\} \gamma / /\{0001\}$ $\alpha$, which is confirmed in Figures 5-8 (panel d in all figures). The probability mechanism that which could explain the relationship of the orientation in this study was the formation of massive- $\gamma$. This massive- $\gamma$ transform was nucleated at the longitudinal grain boundary of the prior $\alpha / \alpha$ grain, which confirmed this massive transformation mechanism (Figure 8). Although the initial nucleus may be coherent, twinning that occurred on the $\{111\}$ plane, which is not the original interface, would result in a massively transformed gamma that no longer had a simple orientation relationship with the alpha matrix ${ }^{7}$. The formation of massive- $\gamma$ is clearly explained in earlier publications [e.g., References 7,8] that identified a competition between the growth of lamellae and the growth of massive- $\gamma$ under the cooling conditions that were used to refine the microstructures. The results of all cooling rates with the two compositions (i.e., Ti-46Al-4Nb$2 \mathrm{Mo}$ and $\mathrm{Ti}-46 \mathrm{Al}-4 \mathrm{Nb}-2 \mathrm{Cr}$ ) found that the alloy with the $\mathrm{Cr}$ addition as the quaternary alloying element promoted a massive transformed mechanism that was greater than the Mo addition; however, Mo promoted a greater formation of lamellar structure compared with $\mathrm{Cr}^{17}$. The use of $\mathrm{Nb}$ as the alloying element generally slows down the formation of lamellar microstructures, which implies that $\mathrm{Nb}$ may be related to its low diffusivity, and $\mathrm{Nb}$ is a slow diffuser in both $\mathrm{TiAl}$ and $\mathrm{Ti}_{3} \mathrm{Al}$. Indeed, $\mathrm{Nb}$ has a diffusion coefficient that is approximately an order of magnitude lower than that of $\mathrm{Ti}^{18,19}$. Interestingly, $\mathrm{Cr}$ is also a slow diffuser in both $\mathrm{TiAl}$ and $\mathrm{Ti}_{3} \mathrm{Al}$ similar with $\mathrm{Nb}^{18}$. Thus, $\mathrm{Nb}$ and $\mathrm{Cr}$ both effectively extend the massive regime of the nucleated massive- $\gamma$ transformation of Ti-46Al-4Nb-2Cr more than in Ti-46Al-4Nb-2Mo. Interestingly, we found that increasing the quenching rate (from OQ to WQ) led to a reduction in the volume fraction of massive- $\gamma$ for all of the compositions, which confirmed the results of previous research [e.g., Reference 16].

\section{Conclusions}

1. The presence of Mo in the TiAlNb alloys affected the quantity of the $\beta$ phase and facilitated the stability of the lamellar structures. Ti-46Al-4Nb-2Mo in asreceived form had the highest volume fraction of $\beta$ phase.

2. EBSD revealed that adding Mo and $\mathrm{Cr}$ affected the occurrence of massive- $\gamma$, and the addition of $\mathrm{Cr}$ improved the nucleation and growth of massive- more than the addition of Mo. In addition, the massive- $\gamma$ transformation occurred without forming lamellar structure in alloys with the addition of $\mathrm{Cr}$.

3. The massive- $\gamma$ transformed phase was nucleated at the $\alpha$-parent phase grain boundary and grew with the associated orientation relationship with the $\alpha$-parent phase matrix that was inherited from twinning during transformation.

4. Increasing the cooling rate decreased the volume fraction of massive- $\gamma$ structure. 


\section{References}

1. Wu X. Review of alloy and process development of TiAl alloys. Intermetallics. 2006; 14 (10-11):1114-1122. http://dx.doi. org/10.1016/j.intermet.2005.10.019

2. Yamaguchi M, Inui $\mathrm{H}$ and Ito K. High-temperature structural intermetallics. Acta Materiallia. 2000; 4(1):307-322. http:// dx.doi.org/10.1016/S1359-6454(99)00301-8

3. Apple F and Wagner R. Microstructure and deformation of two-phase $\gamma$-titanium aluminides. Materials Science and Engineering: R. 1998; (22):187-268.

4. Kim YW. Gamma titanium aluminide: their status and future. JOM. 1995; 47(7):39.

5. Sreenivasulu G, Singh AK, Mukhopadhyay NK and Sastry GVS. Effect of alloying and aging on morphological changes from lamellar to equiaxed microstructure of $\alpha_{2}+\gamma$ titanium aluminides. Metallurgical and Materials Transactions A. 2001; 36(10):2603-2607.

6. Leonard KJ and Vasudevan VK. Phase equilibria and solid state transformations in $\mathrm{Nb}$-rich $\mathrm{Nb}$ - Ti-Al intermetallic alloys. Intermetallics. 2000; 8(9-11):1257-1268. http://dx.doi. org/10.1016/S0966-9795(00)00056-X

7. $\mathrm{Wu} \mathrm{X}, \mathrm{Hu} \mathrm{D}$, Loretto $\mathrm{MH}$ and Huang AJ. The influence of interrupted cooling on the massive transformation in Ti46Al8Nb. Intermetallics. 2007; 15(9):1147-1155. http:// dx.doi.org/10.1016/j.intermet.2007.02.002

8. Wu X, Saage H, Huang AJ, Hu D and Loretto MH. Microstructures and tensile properties of massively transformed and aged $\mathrm{Ti} 46 \mathrm{~A} 18 \mathrm{Nb}$ and Ti46A18Ta alloys. Intermetallics. 2009; 17(1-2):32-38. http://dx.doi.org/10.1016/j.intermet.2008.09.006

9. Prasad U and Chaturvedi MC. Influence of alloying elements on the kinetics of massive transformation in gamma titanium aluminides. Metallurgical and Materials Transactions A. 2003; 34(10):2053-2066. http://dx.doi.org/10.1007/s11661003-0270-2

10. Hu D, Huang AJ and Wu X. On the massive phase transformation regime in TiAl alloys: The alloying effect on massive/lamellar competition. Intermetallics. 2007; 15(3):327-332. http://dx.doi. org/10.1016/j.intermet.2006.07.007

11. Dey SR, Bouzy E and Hazotte A. EBSD characterisation of massive $\gamma$ nucleation and growth in a TiAl-based alloy. Intermetallics. 2006; 14(4):444-449. http://dx.doi.org/10.1016/j. intermet.2005.08.010

12. Imayev RM, Imayev VM, Oehring M and Appel F. Alloy design concepts for refined gamma titanium aluminide based alloys. Intermetallics. 2007; 15(4):459. http://dx.doi.org/10.1016/j. intermet.2006.05.003

13. Kimura $\mathrm{M}$ and Hashimoto K. High-temperature phase equilibria in Ti-AI-Mo system. Journal of Phase Equilibria. 1999; 20(3):228.

14. Singh $A K$ and Banerjee D. Transformations in $\alpha_{2}+\gamma$ titanium aluminide alloys containing molybdenum: Part II. Heat treatment. Metallurgical and Materials Transactions A. 1997; 28(9):1745-1753. http://dx.doi.org/10.1007/s11661-997-0106-6

15. Zhung XD, Godfrey S, Weaver M, Strangwood M, Kaufman MJ and Loretto $\mathrm{MH}$. The massive transformation in Ti-Al alloys: Mechanistic observations. Acta Materiallia. 1996; 44(9):3723. http://dx.doi.org/10.1016/1359-6454(95)00453-X

16. Veeraraghavan D, Wang P and Vasudeven VK. Kinetics and thermodynamics of the $\alpha \rightarrow \gamma$ massive transformation in a Ti47.5 at.\% Al alloy. Acta Materiallia. 1999; 47(11):3313-3330. http://dx.doi.org/10.1016/S1359-6454(99)00195-0

17. Yun JH, Oh MH, Nam SW, Wee DM, Inui H and Yamaguchi M. Microalloying Effects in TiAl+Mo Alloys. Materials Science and Engineering: A. 1997; 230-240:702-708.

18. Herzig Chr, Przeorski T, Friesel M, Hisker F and Divinski S. Tracer solute diffusion of $\mathrm{Nb}, \mathrm{Zr}, \mathrm{Cr}, \mathrm{Fe}$, and $\mathrm{Ni}$ in $\gamma$-TiAl: effect of preferential site occupation. Intermetallics. 2001; 9(6):461-472. http://dx.doi.org/10.1016/S0966-9795(01)00025-5

19. Mishin Y and Herzig C. Diffusion in the Ti-Al system. Acta Materiallia. 2000; 48(3):589-632. http://dx.doi.org/10.1016/ S1359-6454(99)00400-0 